\title{
Frequency of deep vein thrombosis at admission for acute stroke and associated factors: a cross-sectional study
}

Takahisa Mori $^{1^{*}}$ (D, Kazuhiro Yoshioka ${ }^{1}$ and Yuhei Tanno ${ }^{1,2}$

\begin{abstract}
Background: Intermittent pneumatic compression (IPC) is commonly used to prevent deep vein thrombosis (DVT) during hospitalization in patients with acute stroke. However, if DVT exists at admission, IPC of the legs with DVT may cause migration of the thrombi, resulting in pulmonary emboli. Whole-leg ultrasonography (WI-US) is a practical tool to detect DVT; however, wI-US is not always performed at admission in all stroke patients. This retrospective cross-sectional study aimed to investigate DVT frequency and identify significant factors indicating the presence of DVT at admission for acute stroke.

Methods: We included patients admitted within 24 h of stroke onset between 2017 and 2019. Patients who did not undergo blood tests for D-dimer or wl-US within $72 \mathrm{~h}$ of arrival were excluded. We collected patient data on age; sex; anthropometric variables; presence of DVT on wI-US; and biomarkers such as D-dimer, high-sensitivity Creactive protein (hs-CRP), and lipids.
\end{abstract}

Results: Of 1129 acute stroke patients, 917 met our inclusion criteria. DVT was detected in 161 patients (17.6\%). Patients with DVT were older; were more likely to be female; had lower body weight; had higher D-dimer and hsCRP levels; had lower albumin, hemoglobin, and triglyceride levels; and had higher National Institutes of Health Stroke Scale and pre-stroke modified Rankin scale scores than patients without DVT ( $n=756)$. In addition, multiple logistic regression analysis showed that sex (female) and D-dimer levels $(\geq 1.52 \mu \mathrm{g} / \mathrm{mL}$ ) were independent significant factors for the presence of DVT. Among 161 patients with DVT, 78 (48.4\%) had both these significant factors. Among 756 patients without DVT, 602 (79.6\%) had no or one significant factor. The odds ratio of the presence of DVT in patients with both significant factors was 6.29, using patients without any significant factors as the group for comparison.

Conclusions: The frequency of DVT is high in acute stroke patients at admission. Female sex and a high D-dimer level were independent significant factors for the presence of DVT. Therefore, in patients with these two significant factors at admission, IPC should be avoided or wI-US should be performed before IPC.

Keywords: Deep vein thrombosis, D-dimer, Frequency, Intermittent pneumatic compression, Stroke, Ultrasonography

\footnotetext{
*Correspondence: morit-koc@umin.net

'Department of Stroke Treatment, Shonan Kamakura General Hospital,

Okamoto 1370-1, 247-8533 Kamakura City, Kanagawa, Japan

Full list of author information is available at the end of the article
}

(c) The Author(s). 2021 Open Access This article is licensed under a Creative Commons Attribution 4.0 International License, which permits use, sharing, adaptation, distribution and reproduction in any medium or format, as long as you give appropriate credit to the original author(s) and the source, provide a link to the Creative Commons licence, and indicate if changes were made. The images or other third party material in this article are included in the article's Creative Commons licence, unless indicated otherwise in a credit line to the material. If material is not included in the article's Creative Commons licence and your intended use is not permitted by statutory regulation or exceeds the permitted use, you will need to obtain permission directly from the copyright holder. To view a copy of this licence, visit http://creativecommons.org/licenses/by/4.0/ The Creative Commons Public Domain Dedication waiver (http://creativecommons.org/publicdomain/zero/1.0/) applies to the data made available in this article, unless otherwise stated in a credit line to the data. 


\section{Background}

Venous thromboembolism (VT) is a common cause of death and morbidity in patients with acute stroke during hospitalization [1]. Anticoagulants reduce the frequency of pulmonary emboli due to VT; however, this benefit is offset by an increase in the frequency of extracranial hemorrhage [2]. In addition, anticoagulants cannot be administered to patients with hemorrhagic stroke. Therefore, intermittent pneumatic compression (IPC) is commonly used to reduce the risk of deep vein thrombosis (DVT) during hospitalization [3]. A DVT frequency of 8.0 or $8.7 \%$ at admission was reported from Polish institutions [4, 5]; however, the DVT frequency at admission has been unknown in Japan. If the DVT frequency is high in Japan and IPC of the legs with DVT is started in patients with DVT at the time of admission, IPC may cause migration or fragmentation of thrombi and lead to pulmonary embolism. During hospitalization, D-dimer levels are often elevated in patients with DVT [6]. Whole-leg ultrasonography (wl-US) is a practical tool to detect DVT in outpatients or inpatients [7]. wlUS or D-dimer measurement should always be performed for detecting DVT at admission for stroke; however, wl-US is not routinely performed at admission in many facilities. Therefore, a practical index to estimate the presence of DVT at stroke admission is necessary. Our retrospective cross-sectional study aimed to investigate DVT frequency at admission and identify significant factors specific to the presence of DVT at admission for acute stroke.

\section{Methods}

To investigate DVT frequency at admission and identify related factors, we included patients admitted within $24 \mathrm{~h}$ of stroke onset between March 2017 and March 2019. We excluded patients whose plasma D-dimer level was not examined within $24 \mathrm{~h}$ of arrival or in whom whole-leg US was not performed within $72 \mathrm{~h}$ of arrival. We collected patient data on age, sex, anthropometric variables, and US findings of DVT. We evaluated biomarkers such as hemoglobin (Hb), serum albumin (Alb), high-sensitivity C-reactive protein (hs-CRP), glucose, HbA1c, total cholesterol, high-density lipoprotein cholesterol, triglycerides (TG), aspartate aminotransferase (AST), alanine aminotransferase (ALT), AST/ALT ratio, and plasma D-dimer. In addition, we evaluated the $\mathrm{Na}$ tional Institutes of Health Stroke Scale (NIHSS) score [8] and pre-stroke modified Rankin scale (mRS) score at admission [9]. The low-density lipoprotein cholesterol concentration was calculated using the Friedewald formula: low-density lipoprotein cholesterol = total cholesterol - high-density lipoprotein cholesterol - TG/5. Ddimer levels were measured using latex turbidimetric immunoassay (LIAS AUTO D-Dimer NEO, Sysmex Co.,
Hyogo, Japan) [10]. DVT was diagnosed according to the findings of wl-US (Xario, Canon Medical Systems Co., Tochigi, Japan), performed by trained radiologists [11]. DVT was diagnosed based on the following US findings: presence of a non-compressible segment or flow impairment on color Doppler imaging [12]. Compression was performed at $2 \mathrm{~cm}$ intervals.

\section{Statistical analysis}

Non-normally distributed continuous variables are expressed as medians and interquartile ranges. We compared all possible pairs of variables with significant differences between patients with and without DVT. A dummy variable was used to represent categorical data, such as data on sex, and Spearman rank correlation coefficient $\left(r_{\mathrm{s}}\right)$ was calculated to measure the strength of the relationships. We defined $0 \leq\left|r_{\mathrm{s}}\right|<0.1$ as no correlation, $0.1 \leq\left|r_{\mathrm{s}}\right|<0.4$ as a weak correlation, $0.4 \leq\left|r_{\mathrm{s}}\right|<$ 0.6 as a moderate correlation, and $0.6 \leq\left|r_{\mathrm{s}}\right|$ as a strong correlation. Multicollinearity was defined as the presence of a moderate or strong correlation between variables. When variables were moderately or strongly correlated with one another, we adopted the variable with a larger chi-squared value. After excluding variables with multicollinearity, we conducted a multiple logistic regression analysis to identify independent variables indicating the presence of DVT. We estimated the threshold values of independent variables indicating the presence of DVT using area under the curve values derived from the receiver operating characteristic curves of the logistic regression model. Statistical significance was set at a $P$ value $<0.05$. We used JMP software (version 16.0; SAS Institute, Cary, NC, USA) for all statistical analyses.

\section{Results}

During the study period, 1129 acute stroke patients were admitted, and 917 met our inclusion criteria. Patient characteristics are summarized in Table 1. DVT was detected in $161(17.6 \%)$ of 917 patients at admission. Patients with DVT $(n=161)$ were older; were more likely to be female; had lower body weight; had higher plasma D-dimer and hs-CRP levels; had lower Hb, serum Alb, TG, and ALT levels; had a higher AST/ALT ratio; and had higher NIHSS and pre-stroke mRS scores than patients without DVT $(n=756)$ (Table 2$)$. After excluding variables with significant differences between the two groups and variables with multicollinearity (Additional file 1), multiple logistic regression analysis showed that sex and D-dimer levels were independent variables for the presence of DVT (Table 3). Receiver operating characteristic curves demonstrated that female sex and a Ddimer level of $\geq 1.52 \mu \mathrm{g} / \mathrm{mL}$ were independent factors for the presence of DVT at the time of stroke admission (Table 4). Among 161 patients with DVT, 78 (48.4\%) 
Table 1 Patient characteristics

\begin{tabular}{|c|c|}
\hline Variables & Values \\
\hline $\mathrm{N}$ & 917 \\
\hline DVT, n (\%) & $161(17.6 \%)$ \\
\hline Ischemic stroke, n (\%) & $734(80.0 \%)$ \\
\hline Female sex, n (\%) & $449(49.0 \%)$ \\
\hline Age, years & $80(71,86)$ \\
\hline $\mathrm{BMl}, \mathrm{kg} / \mathrm{m}^{2}$ & $22.0(19.5,24.4)$ \\
\hline BW, kg & $55(47,65)$ \\
\hline $\mathrm{Hb}, \mathrm{g} / \mathrm{dL}$ & $13.3(12,14.6)$ \\
\hline $\mathrm{Plt}, / \mu \mathrm{L}$ & $20.8(17.1,25.5)$ \\
\hline Alb, mg/dL & $3.9(3.6,4.2)$ \\
\hline AST, U/L & $23(19,29)$ \\
\hline $\mathrm{ALT}, \mathrm{U} / \mathrm{L}$ & $16(12,23)$ \\
\hline AST/ALT ratio & $1.4(1.1,1.8)$ \\
\hline Glucose, mg/dL & $122(105,151)$ \\
\hline $\mathrm{HbA1c}$ \% (NGSP) & $5.8(5.5,6.4)$ \\
\hline $\mathrm{TC}, \mathrm{mg} / \mathrm{dL}$ & $196(168,225)$ \\
\hline $\mathrm{LDL}, \mathrm{mg} / \mathrm{dL}$ & $110(85,134)$ \\
\hline $\mathrm{HDL}, \mathrm{mg} / \mathrm{dL}$ & $56.2(46.1,68.4)$ \\
\hline $\mathrm{TG}, \mathrm{mg} / \mathrm{dL}$ & $93(65,136)$ \\
\hline $\mathrm{hs}-\mathrm{CRP}, \mathrm{mg} / \mathrm{dL}$ & $0.14(0.05,0.53)$ \\
\hline D-dimer, $\mu \mathrm{g} / \mathrm{mL}$ & $1.4(0.7,3.1)$ \\
\hline NIHSS at admission & $5(2,16)$ \\
\hline Pre-stroke mRS & $0(0,3)$ \\
\hline
\end{tabular}

All values except for categorical data are represented as median (interquartile range)

Abbreviations: $A L T$ alanine aminotransferase, AST aspartate aminotransferase, $B W$ body weight, $H D L$ high-density lipoprotein cholesterol, $h s-C R P$ highsensitivity C-reactive protein, DVT deep vein thrombosis, LDL low-density lipoprotein cholesterol, $m R S$ modified Rankin scale score, NGSP National Glycohemoglobin Standardization Program, N number, NIHSS National Institutes of Health Stroke Scale, TC total cholesterol, TG triglyceride

had both these significant factors. Among 756 patients without DVT, 602 (79.6\%) had no or one significant factor. The odds of the presence of DVT was 0.506 in patients with both significant factors, 0.182 in patients with one significant factor, and 0.081 in patients without any significant factors. On using patients without any significant factors as the group for comparison, the odds ratio of the presence of DVT was 6.29 in patients with both significant factors (Table 5).

\section{Discussion}

Our results demonstrated that DVT was present in $17.6 \%$ of acute stroke patients at admission, and female sex and a high D-dimer level were significant factors indicating the presence of DVT at admission. The odds ratio of the presence of DVT in patients with both significant factors was 6.29. Therefore, in patients with both these significant factors at admission, IPC should be avoided or wl-US should be performed before IPC.

wl-US has been shown to have high sensitivity $(94.0 \%)$ and specificity (97.3\%) for detecting DVT [7]. However, wl-US is not always performed for stroke patients in most facilities. In contrast, D-dimer levels can be measured easily in any institution. A cut-off value of $0.5 \mu \mathrm{g} /$ $\mathrm{mL}$ for D-dimer levels showed a sensitivity of $82.9 \%$ and specificity of $32.7 \%$ for detecting DVT in patients during hospitalization [6]. Furthermore, our results demonstrated that D-dimer was a significant factor for the presence of DVT at stroke admission. Therefore, Ddimer levels should be examined routinely at stroke admission.

According to previous studies, DVT was found on day 3 after stroke onset in $8.0 \%$ of acute stroke patients and within 7 days of stroke onset in $8.7 \%$ of acute stroke patients in Polish institutions $[4,5]$. In comparison, the DVT frequency was high in our study at $17.5 \%$; this may be because our patients were older than those in previous studies, and US was performed within $72 \mathrm{~h}$ of arrival in our patients, compared to the performance of US within 7 days of stroke onset in a previous study [4, 5]. Female sex, elevated CRP levels, and pre-stroke disability were risk factors for DVT within 7 days of stroke onset, and elevated CRP and pre-stroke disability were independent risk factors for the presence of DVT [5]. However, D-dimer was not examined in the previous study [5]. Elevated CRP levels and pre-stroke disability were also found to be significant factors for the presence of DVT in our patients (Table 2). However, they were not independent because of multicollinearity.

The incidence of DVT has been reported to be approximately $50 \%$ within 2 weeks in the absence of heparin prophylaxis in patients with acute hemiplegic stroke [13]. Patients with proximal subclinical DVT had a $15 \%$ risk of fatal pulmonary embolism [13, 14]. Untreated below-knee DVT is associated with a $20 \%$ risk of proximal extension [13], and the pulmonary embolism rate is reportedly $6.1 \%$ in trauma patients with below-knee DVT [15]. On admission to the stroke rehabilitation unit, the prevalence of DVT in patients with stroke ranges from 12 to $40 \%$ [16]. Therefore, the onset of DVT during hospitalization in primary stroke centers must be prevented. When DVT is not detected at admission, IPC can be used safely. If DVT is detected at admission in patients with ischemic stroke, anticoagulants may be started soon. The disuse of IPC may not induce thrombi fragmentation in patients with DVT at admission. Early anticoagulant therapy may protect against thromboembolism caused by DVT present at admission, and early IPC or anticoagulant therapy may prevent DVT development after admission. Overall, the frequency of symptomatic or critical DVT may decrease 
Table 2 Comparison of variables between the two groups

\begin{tabular}{|c|c|c|c|c|}
\hline & Patients with DVT & Patients without DVT & Chi-square value & $P$-value \\
\hline $\mathrm{N}$ & 161 & 756 & & \\
\hline Ischemic stroke, n (\%) & $132(82.0 \%)$ & $602(79.6 \%)$ & 0.5 & 0.4924 \\
\hline Female sex, n (\%) & $106(65.8 \%)$ & $343(45.4 \%)$ & 22.4 & $<0.0001$ \\
\hline Age, years & $82(77,89)$ & $79(71,86)$ & 21.0 & $<0.0001$ \\
\hline $\mathrm{BMI}, \mathrm{kg} / \mathrm{m}^{2}$ & $21.5(19.1,23.7)$ & $22.1(19.6,24.5)$ & 3.6 & 0.0569 \\
\hline BW, kg & $52(44,60)$ & $56(47,65)$ & 11.5 & 0.0007 \\
\hline $\mathrm{Hb}, \mathrm{g} / \mathrm{dL}$ & $12.6(11.5,13.8)$ & $13.4(12.3,13.9)$ & 21.3 & $<0.0001$ \\
\hline $\mathrm{Plt}, / \mu \mathrm{L}$ & $20.5(17.1,25.5)$ & $20.9(17.2,25.7)$ & 0.2 & 0.6772 \\
\hline $\mathrm{Alb}, \mathrm{mg} / \mathrm{dL}$ & $3.7(3.4,4.1)$ & $4.0(3.7,4.2)$ & 25.7 & $<0.0001$ \\
\hline AST, U/L & $22(19,31)$ & $23(19,28)$ & 0.0 & 0.9744 \\
\hline$A L T, U / L$ & $15(12,21)$ & $17(12,23)$ & 6.3 & 0.0123 \\
\hline AST/ALT ratio & $1.53(1.22,1.87)$ & $1.38(1.13,1.73)$ & 10.7 & 0.0011 \\
\hline Glucose, mg/dL & $122(106,149)$ & $123(105,153)$ & 0.4 & 0.5314 \\
\hline $\mathrm{HbA1c}$ \% (NGSP) & $5.8(5.5,6.3)$ & $5.8(5.5,6.4)$ & 0.2 & 0.6810 \\
\hline $\mathrm{TC}, \mathrm{mg} / \mathrm{dL}$ & $194(159,226)$ & $197(170,224)$ & 0.3 & 0.5873 \\
\hline $\mathrm{LDL}, \mathrm{mg} / \mathrm{dL}$ & $110(82,131)$ & $111(87,135)$ & 1.2 & 0.2794 \\
\hline $\mathrm{HDL}, \mathrm{mgl} / \mathrm{dL}$ & $56.7(44.3,71.7)$ & $55.8(46.2,68.2)$ & 0.1 & 0.7125 \\
\hline $\mathrm{TG}, \mathrm{mg} / \mathrm{dL}$ & $82(61,123)$ & $95(66,141)$ & 4.8 & 0.0279 \\
\hline hs-CRP, mg/dL & $0.17(0.07,0.77)$ & $0.13(0.05,0.47)$ & 6.6 & 0.0103 \\
\hline D-dimer, $\mu \mathrm{g} / \mathrm{mL}$ & $2.7(1.3,6.0)$ & $1.2(0.6,2.6)$ & 60.2 & $<0.0001$ \\
\hline NIHSS at admission & $8(3,18)$ & $5(2,15)$ & 12.3 & 0.0004 \\
\hline Pre-stroke mRS & $2(0,3.5)$ & $0(0,3)$ & 16.1 & $<0.0001$ \\
\hline
\end{tabular}

All values except for categorical data are represented as median (interquartile range)

Alb albumin, $A L T$ alanine aminotransferase, $A S T$ aspartate aminotransferase, $B M I$ body mass index, $B W$ body weight, $H b$ hemoglobin, $H D L$ high-density lipoprotein cholesterol, hs-CRP high-sensitivity C-reactive protein, DVT deep vein thrombosis, LDL low-density lipoprotein cholesterol, $m R S$ modified Rankin scale score, $N$ number, NGSP National Glycohemoglobin Standardization Program, NIHSS National Institutes of Health Stroke Scale, P probability, PIt platelet, TC total cholesterol, TG triglyceride

during hospitalization in primary stroke centers. Plasma D-dimer levels must be measured at the time of stroke, and patients with both significant factors, i.e., female sex and a D-dimer level $\geq 1.52 \mu \mathrm{g} / \mathrm{mL}$, should immediately undergo wl-US, if possible.

Table 3 Multiple logistic regression for deep vein thrombosis presence at the admission of stroke using receiver operating characteristics curves

\begin{tabular}{lllll}
\hline & Odds ratio & \multicolumn{1}{l}{$\boldsymbol{P}$-value } & AUC & BIC \\
\hline & & $<0.0001$ & 0.687 & 774 \\
Sex & $2.04(1.40-3.00)$ & 0.0002 & & \\
D-dimer & $1.05(1.02-1.08)$ & 0.0003 & & \\
TG & $1.00(0.99-1.00)$ & 0.0560 & & \\
hs-CRP & $1.08(0.99-1.17)$ & 0.0680 & & \\
ALT & $0.99(0.98-1.00)$ & 0.2479 & & \\
NIHSS & $1.01(0.99-1.03)$ & 0.2698 & & \\
\hline
\end{tabular}

$A L T$ alanine aminotransferase, AUC area under the curve, BIC Bayesian information criterion, $h s$-CRP high-sensitivity C-reactive protein, NIHSS National Institutes of Health Stroke Scale at admission, $P$ probability, TG triglyceride

\section{Limitations}

Our study had several limitations. First, the sample size was small, and the study had a retrospective, crosssectional design. Second, although US has a sensitivity of $94 \%$ for detecting DVT, it cannot always detect DVT. Third, because most of the patients were Japanese, generalization of the study outcomes to non-Japanese populations may not be possible. There might be racial differences in the association between DVT-related factors and threshold values of factors associated with the

Table 4 Threshold values for DVT presence using receiver operating characteristics curves from logistic regression analysis

\begin{tabular}{lllllll}
\hline & $\begin{array}{l}\text { Sens } \\
(\%)\end{array}$ & $\begin{array}{l}\text { Spec } \\
\text { (\%) }\end{array}$ & $\begin{array}{l}\text { Odds } \\
\text { ratio }\end{array}$ & P-value & AUC & BIC \\
\hline Sex $(1$ vs. $<1)$ & 65.8 & 54.5 & $2.31(1.62-3.31)$ & $<0.0001$ & 0.602 & 843 \\
D-dimer $(\geq 1.52$ & 70.0 & 59.6 & $1.06(1.03-1.09)$ & $<0.0001$ & 0.695 & 836 \\
vs. $<1.52) \mu \mathrm{g} / \mathrm{mL}$ & & & & & & \\
\hline AUC a & & & & &
\end{tabular}

$A U C$ area under the curve, BIC Bayesian information criterion, DVT deep vein thrombosis, $P$ probability, Sens sensitivity, Spec specificity, $T G$ triglyceride 
Table 5 Cross tabulation table between patients with significant factors, DVT, Odds, and Odds ratio

\begin{tabular}{llll}
\hline & DVT presence & DVT absence & Odds \\
\hline $\mathrm{N}$ & 161 & 756 & Odds ratio \\
Patients with the two significant factors & 78 & 154 & 0.5065 \\
Patients with one significant factor & 62 & 341 & 0.1818 \\
Patients without any significant factors & 21 & 261 & 0.0805 \\
\hline
\end{tabular}

The two significant factors are female sex and D-dimer $\geq 1.52 \mu \mathrm{g} / \mathrm{mL}$

$D V T$ deep vein thrombosis, $N$ number

presence of DVT. A prospective study including US and plasma D-dimer examination is required to determine the frequency of DVT at stroke admission and significant associated factors.

\section{Conclusions}

The frequency of DVT at admission in acute stroke patients was high at $17.6 \%$ in our institution. Female sex and high D-dimer levels were significant factors for the presence of DVT. Therefore, in patients with these two significant factors at admission, IPC should be avoided or wl-US should be performed before IPC.

\author{
Abbreviations \\ Alb: Albumin; ALT: Alanine aminotransferase; AST: Aspartate \\ aminotransferase; DVT: Deep vein thrombosis; hs-CRP: High-sensitivity C- \\ reactive protein; IPC: Intermittent pneumatic compression; mRS: Modified \\ Rankin scale; NIHSS: National Institutes of Health Stroke Scale; \\ US: Ultrasonography; VT: Venous thromboembolism; wI-US: Whole-leg \\ ultrasonography
}

\section{Supplementary Information}

The online version contains supplementary material available at https://doi. org/10.1186/s12959-021-00315-5

\section{Additional file 1.}

\section{Acknowledgements}

We would like to thank Nozomi Chiba, BA., for her secretarial assistance and the ultrasonographers at our stroke center for specialized support.

\section{Authors' contributions}

Conceptualization: T.M. Methodology: T.M. Validation: T.M. Formal analysis: T.M. Investigation: T.M., K.Y., Y.T. Resources: T.M., K.Y., Y.T. Data curation: T.M. K.Y., Y.T. Writing-original draft preparation: T.M. Writing-review and editing: T.M. Visualization: T.M. All authors have read and agreed to the published version of the manuscript.

\section{Funding}

This research did not receive any specific grant from funding agencies in the public, commercial, or not-for-profit sectors.

\section{Availability of data and materials}

The datasets analyzed during the current study are available from the corresponding author on reasonable request.

\section{Declarations}

\section{Ethics approval and consent to participate}

All procedures were performed in accordance with the ethical standards of the institution and the 1964 Helsinki Declaration. The Tokushukai Group
Ethics Committee approved this retrospective study with a waiver for informed consent (TGE01723-024). Study participant enrollment was based on an opt-out model, which the ethical committee permitted.

Consent for publication

Not applicable.

\section{Competing interests}

The authors declare that they have no competing interests.

\section{Author details}

${ }^{1}$ Department of Stroke Treatment, Shonan Kamakura General Hospital, Okamoto 1370-1, 247-8533 Kamakura City, Kanagawa, Japan. ²Department of Neurology, Nakatsugawa Municipal General Hospital, Komaba 1522-1, Gifu 508-8502 Nakatsugawa City, Japan.

Received: 8 July 2021 Accepted: 22 August 2021

Published online: 06 September 2021

\section{References}

1. House of Commons Health Committee. The prevention of venous thromboembolism in hospitalised patients. Second Report of Session 2004 05, HC 99. London: Stationery Office; 2005.

2. Sandercock PA, Counsell C, Kamal AK. Anticoagulants for acute ischaemic stroke. Cochrane Database Syst Rev. 2008:CD000024. https://doi.org/10.1 002/14651858.CD000024.pub3.

3. CLOTS (Clots in Legs Or sTockings after Stroke) Trials Collaboration. Effectiveness of intermittent pneumatic compression in reduction of risk of deep vein thrombosis in patients who have had a stroke (CLOTS 3): a multicentre randomised controlled trial. Lancet. 2013·382.516-24.

4. Bembenek J, Karlinski M, Kobayashi A, Czlonkowska A. Early stroke-related deep venous thrombosis: risk factors and influence on outcome. J Thromb Thrombolysis. 2011;32:96-102.

5. Bembenek JP, Karlinski M, Kobayashi A, Czlonkowska A. Deep venous thrombosis in acute stroke patients. Clin Appl Thromb Hemost. 2012;18: 258-64

6. Canan A, Halicioglu SS, Gurel S. Mean platelet volume and D-dimer in patients with suspected deep venous thrombosis. J Thromb Thrombolysis. 2012:34:283-7.

7. Bhatt M, Braun C, Patel P, Patel P, Begum H, Wiercioch W, et al. Diagnosis of deep vein thrombosis of the lower extremity: a systematic review and meta-analysis of test accuracy. Blood Adv. 2020;4:1250-64.

8. Lyden P, Brott T, Tilley B, Welch KM, Mascha EJ, Levine S, et al. Improved reliability of the NIH Stroke Scale using video training. NINDS TPA Stroke Study Group. Stroke. 1994:25:2220-6.

9. van Swieten JC, Koudstaal PJ, Visser MC, Schouten HJ, van Gijn J. Interobserver agreement for the assessment of handicap in stroke patients. Stroke. 1988;19:604-7.

10. Suzuki H, Masaki Y, Okubo M, Yotsui S, Ogura M, Imanishi K, et al. A comparative study of Sysmex Latex Test BL-2 P-FDP and LIAS AUTO DDimer NEO with similar assay reagents of two other companies on the fully automated blood coagulation analyzer CS-5100. Sysmex J Int. 2014;24. https://www.sysmex.co.jp/en/products_solutions/library/journal/vol24_no1/ vol24_1_10.pdf

11. Konstantinides SV, Torbicki A, Agnelli G, Danchin N, Fitzmaurice D, Galie N, et al. 2014 ESC guidelines on the diagnosis and management of acute pulmonary embolism. Eur Heart J. 2014;35:3033-69, 3069a-3069k. 
12. Needleman L, Cronan JJ, Lilly MP, Merli GJ, Adhikari S, Hertzberg BS, et al. Ultrasound for lower extremity deep venous thrombosis: multidisciplinary recommendations from the Society of Radiologists in Ultrasound Consensus Conference. Circulation. 2018:137:1505-15.

13. Kelly J, Rudd A, Lewis R, Hunt BJ. Venous thromboembolism after acute stroke. Stroke. 2001;32:262-7.

14. Khan MT, Ikram A, Saeed O, Afridi T, Sila CA, Smith MS, et al. Deep vein thrombosis in acute stroke - a systemic review of the literature. Cureus. 2017;9:e1982.

15. Olson EJ, Zander AL, Van Gent JM, Shackford SR, Badiee J, Sise CB, et al. Below-knee deep vein thrombosis: an opportunity to prevent pulmonary embolism? J Trauma Acute Care Surg. 2014;77:459-63.

16. Wilson RD, Murray PK. Cost-effectiveness of screening for deep vein thrombosis by ultrasound at admission to stroke rehabilitation. Arch Phys Med Rehabil. 2005:86:1941-8

\section{Publisher's Note}

Springer Nature remains neutral with regard to jurisdictional claims in published maps and institutional affiliations.

Ready to submit your research? Choose BMC and benefit from:

- fast, convenient online submission

- thorough peer review by experienced researchers in your field

- rapid publication on acceptance

- support for research data, including large and complex data types

- gold Open Access which fosters wider collaboration and increased citations

- maximum visibility for your research: over $100 \mathrm{M}$ website views per year

At BMC, research is always in progress.

Learn more biomedcentral.com/submissions 